J. Lake Sci. (湖泊科学), 2014, 26(1): 1-8

http : //www. jlakes. org. E-mail : jlakes@niglas. ac.cn

(c) 2014 by Journal of Lake Sciences

\title{
长江中游通江湖泊江湖关系研究进展
}

\author{
万荣荣, 杨桂山林, 王晓龙, 秦年秀, 戴 雪 \\ (中国科学院南京地理与湖泊研究所湖泊与环境国家重点实验室, 南京 210008)
}

\begin{abstract}
摘 要: 自然通江的洞庭湖和鄱阳湖与长江之间形成复杂的江湖水沙交换关系, 其变化影响着区域洪水灾害防治、水资 源利用、水环境保护和水生态安全维护, 是长江中游水问题的核心. 从长江中游大型通江湖泊江湖关系的概念与内涵、江 湖关系演变过程、江湖关系变化的影响因素及效应等方面, 系统梳理了长江中游通江湖泊江湖关系研究的进展. 针对当 前研究现状和存在的问题, 提出了研究江湖关系表征指标体系是正确认识江湖关系的前提; 定量区分人类活动和气候变 化影响的贡献率是江湖关系研究的重点和难点; 深人跟踪研究三峡等重大工程对江湖关系变化的影响是一项长期任务; 评估江湖关系调整背景下江湖关系的健康状况, 研究以江湖水系重大水利工程群联合调度为核心的江湖关系优化调控 原理,维持江湖两利的长江中游健康河湖系统格局和相互作用关系是江湖关系研究的根本目标.
\end{abstract}

关键词 : 通江湖泊;江湖关系; 长江; 鄱阳湖;洞庭湖;三峡工程

\section{Progress of research on the relationship between the Yangtze River and its connected lakes in the middle reaches}

\author{
WAN Rongrong, YANG Guishan, WANG Xiaolong, QIN Nianxiu \& DAI Xue
}

( State Key Laboratory of Lake Science and Environment, Nanjing Institute of Geography and Limnology, Chinese Academy of Sciences, Nanjing 210008, P. R. China)

\begin{abstract}
The complicated changing water-sediment exchange relationship between the Yangtze River and its naturally connected lakes, Lake Dongting and Lake Poyang, have affected regional flood disaster control, water resources and water environmental protection and maintenance of water ecological security, which has become the core of water problems in the middle reaches of the Yangtze River. The progress of research on river-lake relationship between the Yangtze River and its connected large lakes was systematically reviewed from the point of view of the concept and connotation of river-lake interaction, the evolution process, the influencing factors and effects of changing river-lake relationship. Based on the problems in current research, the following research issues were proposed: how to define a comprehensive index for the river-lake relationship is the premise to correctly understand the relationship between rivers and lakes; how to quantify the effects of human activities and climate change contributions is the emphasis and difficulty of research on the river-lake relationship; it is a long-term task to track the impact of the Three Gorges Project on the river-lake relationship; and it is the ultimate goal to maintain healthy river-lake system pattern in the middle reaches of the Yangtze River which benefits both the Yangtze River and its connected lakes based on the optimization and controlling principles on joint operation of hydraulic engineering group for large river-lake water systems.
\end{abstract}

Keywords: Lakes connected with the Yangtze River; river-lake relationship; Yangtze River; Lake Poyang; Lake Dongting; Three Gorges Project

长江中游地区湖泊密布, 历史上均与长江自然连通, 形成了自然的江、河、湖复合生态系统, 位于其中的 鄱阳湖和洞庭湖两个大型淡水湖泊, 至今仍保持着与长江的自然连通状态. 长江与它们之间相互作用、互为 制约, 长期演变形成的江湖水沙交换关系错综复杂,其变化历经沧桑, 特别是近百年来一系列江湖整治工程

* 国家重点基础研究发展计划“973” 项目 (2012CB417006) 和国家自然科学基金项目 (41171024) 联合资助. 2013 - 03 30 收稿;2013-09-23 收修改稿. 万荣荣(1977～), 女, 博士, 副研究员;E-mail: rrwan@ niglas. ac. cn.

** 通信作者;E-mail: gsyang@ niglas. ac. cn. 
建设等人类活动影响下江湖关系的剧烈调整, 与中游江湖水系愈演愈烈的洪早灾害之间的互馈作用倍受关 注和争议. 长江中游江湖关系的变化影响着区域洪水灾害防治、水资源利用、水环境保护和水生态安全维 护, 是长江中游水问题的核心 ${ }^{[1]}$. 近年来, 三峡工程等上游控制性水利枢纽相继建成运行, 又强力驱动着江 湖关系的新一轮调整. 从宏观层面了解江湖关系的概念、内涵及其表征, 剖析江湖关系变化与江湖水系 “小 水大灾”、水资源季节性短缺、湖泊局部水质下降与富营养化加重以及湖泊和洲滩湿地生态退化等一系列水 问题之间错综复杂的关系, 客观评价三峡工程蓄水运行的影响, 成为政府、社会和学术界共同关注的焦点.

\section{1 江湖关系的概念、内涵与表征}

\section{1 江湖关系的概念}

江湖关系这一名词由来已久, 但迄今尚无公认的定义. 上世纪有关江湖关系的研究主要侧重于荆江与 洞庭湖的关系 ${ }^{[2]}$, 由于荆江与洞庭湖在长江流域治理尤其是防洪治理中具有显著地位, 江湖关系成为水利 行业的专有名词 ${ }^{1}$. 近年来, 鄱阳湖与历史通江的洪湖等与长江水沙交换研究中也越来越多地涉及到江湖关 系的概念 ${ }^{[34]}$, 尤其是三峡工程引起的江湖关系改变对长江中游洞庭湖、鄱阳湖的影响越来越受到学术界的 关注, 从而大大提升了 “江湖关系” 这一概念的关注度, 也大大拓展了江湖关系的概念内涵. 国外有关河湖关 系的研究较少, 仅有零星的关于河一湖水量交换变化特征的研究 ${ }^{[5-6]}$. 与国内外同类河-湖关系相比, 自然通 江的洞庭湖、鄱阳湖与长江之间形成的江湖水力联系及水沙交换关系最为复杂. 洞庭湖接纳长江荆江三口 (调弦口 1958 年建闸堵闭, 现为三口) 分流及湘、资、沅、澧四水来水, 调蓄后在城陵矶与长江汇流, 形成吞吐 长江之势; 鄱阳湖承接上游赣、抚、信、饶、修五河来水, 由湖口北注长江, 与长江相互顶托 (长江间或倒灌人 湖), 长江水情变化直接影响鄱阳湖的水量变化. 长江与洞庭湖、鄱阳湖之间不同的水沙交换特性, 形成了各 具特色的江湖关系, 其复杂性与重要性在世界上是独一无二的. 基于此, 我们将江湖关系定义为连通的河湖 水系之间的相互作用,包括河湖水系之间的水量交换、河床湖盆的自然演变及其产生的物质能量交换. 长江 中游江湖关系特指长江与洞庭湖、鄱阳湖这两个大型通江湖泊的交互关系.

\section{2 江湖关系的内涵}

江湖关系是一个复合现象, 长江与洞庭湖、鄱阳湖的江湖关系具不同的内涵. 洞庭湖是一个过水型的湖 泊, 长江和洞庭湖通过荆江三口分流和城陵矶汇合口作为纽带, 构成江湖分合、相互影响、相互制约的错综复 杂的江湖关系. 长江与洞庭湖关系的内涵不仅包括传统防洪意义上的蓄泄关系, 即荆江河段的泄流能力、荆江 三口分流分沙能力、洞庭湖调蓄洪水能力以及城汉河段的泄流能力 4 个方面 ${ }^{[7-8]}$, 还包括荆江与洞庭湖因水量、 物质能量交换而导致的江、湖冲淤演变与水文情势变化及引起的水资源、水环境和水生态效应. 长江和鄱阳湖 以湖口为汇合口, 构成湖水下泄人江或江水倒灌人湖的错综复杂的江湖关系. 江湖水量交换受到鄱阳湖上游 五河来水和长江水量的双重影响, 其内涵不仅包括鄱阳湖调蓄长江洪水的能力, 还包括长江和鄱阳湖因水量、 物质能量交换而导致的江、湖冲淤演变与水文情势变化及引起的水资源、水环境和水生态效应.

\section{3 江湖关系的表征}

长江中游通江湖泊江湖关系的核心是长江和湖泊之间的水沙交换. $\mathrm{Hu}$ 和郭华 等 $^{[3,9-10]}$ 用鄱阳湖水量净 变化量 (湖口出流量与流域五河来水量之差) 与湖口出流量的比例关系定义为长江一鄱阳湖相互作用指数, 以评价长江一鄱阳湖相互作用的强度. 方春明等 ${ }^{[11]}$ 从长江干流来水对湖口出口的顶托作用、湖口倒流出现的 条件、鄱阳湖对洪水的调节系数等方面定量分析了鄱阳湖与长江干流江湖相互作用的影响规律. 赵军凯 等 ${ }^{[12]}$ 通过构建年尺度江湖水交换作用的经验公式来量化长江与鄱阳湖、洞庭湖江湖水交换作用的强度, 对 于鄱阳湖与长江水交换的情况,还考虑了长江水倒灌对江湖水交换系数产生的影响.

荆江三口分流比、城陵矶水位、螺山水位流量关系是长江与洞庭湖区相互作用关注的焦点. 荆江三口是 联系长江干流与洞庭湖的水沙连接通道, 是长江与洞庭湖关系调整变化的纽带 ${ }^{[2,13-14]}$. 众多学者 ${ }^{[15-17]}$ 从洞庭 湖城陵矶出口水力坡降的变化, 论证了长江水位顶托的变化, 因此湖泊出口水力坡降是长江水流顶托的重 要表征指标之一.

(1) 长江水利委员会水文局. 长江中下游江湖关系指标体系研究, 2012:8. 


\section{2 长江中游江湖关系研究}

长江与中游洞庭湖、鄱阳湖的江湖关系研究主要集中于江湖关系的演变过程、江湖关系变化的影响因 素以及江湖关系变化的效应 3 个方面.

\section{1 江湖关系的演变过程}

2.1 .1 江湖形态及连通性变化 江湖水系形态及连通性变化是江湖关系演变的主要表现形式. Yin 等 $^{[18]}$ 系 $^{2}$ 统分析了长江中游江汉平原和洞庭湖区江湖关系的历史演变过程及其对中游地区防洪的影响. 江湖关系的 演变过程被划分为 3 个阶段: 自全新世晚期至公元 4 世纪, 自然因素为主导的江湖关系演变过程, 古云梦泽 与长江中游连通; 公元 4 世纪至 1650 年, 自然与人为因素同时作用下的江湖关系演变, 其中人类活动的影响 越来越重要, 这一阶段洞庭湖与长江中游连通; 1650 年以来, 人类活动影响下的江湖关系演变, 这一阶段由 于泥沙沉积与土地开垦, 洞庭湖的调蓄能力开始下降. Du 等 ${ }^{[19]}$ 利用遥感方法分析了洞庭湖 $1930 \mathrm{~s} 、 1950 \mathrm{~s}$ 、 $1970 \mathrm{~s}$ 以及 2000 年的面积变化及其成因, 结果表明 2000 年比 $1930 \mathrm{~s}$ 洞庭湖的面积减小了 $58.06 \%$, 其中以 $1950 \mathrm{~s}-1970 \mathrm{~s}$ 湖泊萎缩速率最快,与该时期大规模的土地开剭相关.

2.1 .2 江湖水沙交换变化 江湖水沙交换变化是江湖关系演变的核心. 荆江三口分流河道的形成演化过程 及其与长江水沙交换量的变化过程是长江与洞庭湖关系变化的直接表现. 1950s 以来, 荆江三口分流分沙以 荆江裁弯、葛洲坝和三峡工程等人类活动为时间节点呈现明显的阶段性特征 ${ }^{[13]}$. 三峡工程蓄水运行之前, 三 口分流分沙总体上呈逐年减小的趋势, 其分流分沙比由 1956-1966 年的 29\%、35\% 减小至 1999-2002 年 的 $14 \% 、 16 \%$, 年断流天数也逐渐增多; 三峡工程蓄水运行以来的 2003-2007 年与 1999-2002 年相比, 三 口分流比由 $14 \%$ 减少为 $12 \%$, 三口分沙比由 $16 \%$ 增加为 $18 \%^{[14,20-21]}$. 长江干流水情与输沙量的变化, 影响 了长江干流与洞庭湖的泥沙交换 ${ }^{[22]}$. 干流至洞庭湖的净输沙量已从 1950-2000 年的平均 $86 \times 10^{6} \mathrm{t} / \mathrm{a}$ 减少 至 2002 年的 $16 \times 10^{6} \mathrm{t} / \mathrm{a}, 2004$ 年降低至 0,2006 年江湖泥沙交换出现了逆转, 洞庭湖往长江干流的净输沙量 达 $14 \times 10^{6} \mathrm{t} / \mathrm{a}^{[23]}$. 三峡水库蓄水运行之后洞庭湖区无论是泥沙沉积量还是淤积量均大幅下降 ${ }^{[21]}$, 这种新的 江湖泥沙交换格局可能对减缓洞庭湖的萎缩起积极作用.

长江干流的水情直接影响到长江与鄱阳湖之间的相互作用. $\mathrm{Hu}$ 等 ${ }^{[3]}$ 采用湖泊水量净变化率等参数定 量分析了江湖水量交换的状态、强度及其年内时间变化特征, 剖析了 1960-2003 年江湖关系 ( 流域效应、长 江效应) 对鄱阳湖水位尤其是典型洪水年洪水位的影响. 鄱阳湖流域来水对鄱阳湖水位及洪水灾害影响占 主导作用, 而长江对鄱阳湖的顶托起辅助作用. 多数情况下, 当流域对鄱阳湖的影响减弱时, 长江对鄱阳湖 的影响逐渐增强, 而当湖水位上涨时, 长江的顶托作用便逐渐削弱, 流域和长江汛期同时遭遇的情况极其少 见. 鄱阳湖出入湖水沙情势分析研究表明 ${ }^{[21]}, 2003$ 年以来, 鄱阳湖五河与湖口的径流量较 2000 年以前均有 所减小, 五河的人湖输沙量减小明显, 仅为 2000 年以前多年平均的 $34.3 \%$, 而湖口的年均输沙量却明显增 加, 为 2000 年以前多年平均的 $149.2 \%$, 鄱阳湖滞留泥沙大幅减少.

\section{2 江湖关系变化的影响因素}

气候变化、构造沉降、水土流失、泥沙淤积、长江河势变化等自然因素是导致江湖关系变化的原因, 但 20 世纪以来的人类活动加速了江湖关系的调整 ${ }^{[19,24]}$.

2.2 .1 自然因素 自然状态下,江湖形态、连通性及水沙交换是一个动态的过程. 卢金友等 ${ }^{[2]}$ 的研究表明, 荆江三口分流分沙在自然状态下的变化趋势是不断减少, 其影响因素主要有口门与干流河道的相对位 置、口门附近干流河道河势变化、分流道的淤积以及洞庭湖的演变等. Zhang 等 ${ }^{[25]}$ 研究表明自 1990 年以 后, 长江倒灌鄱阳湖的发生频率明显降低并出现间歇性特征, 而这一特征与降雨的时间变化规律具有较 好的对应性.

2.2 .2 人类活动 江湖关系的变化是自然与人类活动共同作用的结果, 近几十年来人类活动的影响越发凸 显. 随着调弦口堵口、下荆江系统裁弯、葛洲坝截流、三峡工程等大型水利工程的运转, 江湖关系发生了多次 调整变化, 对长江中下游河道及洞庭湖、鄱阳湖产生了不同程度的影响 ${ }^{[26-27]}$.

下荆江中洲子和上车湾河道分别于 1967 年和 1969 年实施人工裁弯工程, 沙滩子河弯于 1972 年发生自 然裁弯. 裁弯后流程缩短约 $78 \mathrm{~km}$, 比降加大, 河床发生溯源冲刷, 使上游同流量下沿程水位发生不同程度的 
降低, 从而加速了三口分流的递减进程 ${ }^{[2,28]}$. 葛洲坝水利枢纽兴建后, 坝下游河道发生沿程冲刷, 对松滋口枯 水期的分流产生了明显的影响 ${ }^{[2]}$. 三峡工程蓄水运行降低了汛期坝下干流流量、增大了枯季坝下干流流量, 并导致长江输沙率降低了 $31 \%$, 长江中游干流水情的变化进而改变了长江与两湖的交互作用 ${ }^{[22,29-30]}$. 三峡 蓄水运行后由于清水下泄造成荆江河段的冲刷, 沙市附近河段同流量下的水位出现不同程度的降低, 三口 分流河道口门水位相应下降, 造成三口河道分流、分沙量显著减小, 对洞庭湖产生了不容忽视的影响 ${ }^{[31]}$.三 峡工程蓄水通过对荆江三口分流分沙的影响, 改变了洞庭湖的水沙平衡, 与 1951-2002 年相比, 2003-2007 年湖区人湖年平均径流量由 $2966 \times 10^{8} \mathrm{~m}^{3}$ 减少至 $2303 \times 10^{8} \mathrm{~m}^{3}$, 人湖年平均沙量由 $1.65 \times 10^{8} \mathrm{t}$ 减少至 $0.25 \times$ $10^{8} \mathrm{t}^{[21]}$. 数学模型计算表明, 如长江流域遭遇 1998 年洪水, 三峡可使洞庭湖汛期 7-9 月水位下降 $0.3 \sim 0.4 \mathrm{~m}$, 城陵矶最高洪水位削减 $1.24 \mathrm{~m}$; 同时汛末三峡水库拦蓄上游来水, 使得洞庭湖水位提前消落, 枯水提前, 尤其 是 10 月份水位显著下降 ${ }^{[32]}$.

自 2003 年三峡工程蓄水运行以来, 鄱阳湖的水情产生了显著的变化, 尤其是汛前腾空和汛末蓄水这两 个时段 ${ }^{[33]}$. Zhang 等 ${ }^{[34]}$ 采用 GAMs (Generalized Additive Models) 模型模拟证实了三峡工程蓄水运行造成平 均 5\% 的长江来水量损失, 汛末蓄水期减缓了长江对鄱阳湖的顶托效应, 进而加剧了鄱阳湖秋季的旱情. Liu 等 ${ }^{[35]}$ 利用 1973-2011 年多时相卫星遥感数据提取鄱阳湖水面信息, 结合鄱阳湖水量平衡分析, 揭示了三峡 工程蓄水运行引发的长江与鄱阳湖江湖关系变化是近年鄱阳湖汛末水位突变的主控因子之一.

\section{3 江湖关系变化的效应}

长江中游江湖关系的变化与区域洪旱灾害防治、河湖水系水环境保护、洲滩湿地和水域生态安全维护 密不可分.

2.3.1 对防洪的影响 洞庭湖和鄱阳湖两湖作为长江中游防洪体系中极为重要的一环, 分别承担着蓄洪 $160 \times 10^{8} \mathrm{~m}^{3}$ 和 $25 \times 10^{8} \mathrm{~m}^{3}$ 超额洪水的任务 ${ }^{1}$, 两湖在中游江湖水系中的防洪地位不可替代. 20 世纪以来, 长 江高水位的频率呈显著的上升趋势, 鄱阳湖的水位受控于长江水位和流域来水, 当流域汛期延迟而遭遇长 江高水位时, 鄱阳湖的防洪安全将受到威胁 ${ }^{[36-37]}$. 自 1950 年以来, 因土地开怎、防洪大堤的修建、湖泊的萎 缩以及洪水期长江水位升高等原因造成江湖关系改变, 鄱阳湖年最高洪水位呈现显著的上升趋势 ${ }^{[36,38-39]}$.

1980 年以来, 因荆江裁弯致使长江一洞庭湖的江湖关系发生较大变化, 三口人湖水沙减少, 减缓了洞庭 湖的淤积和防洪压力; 但同时荆江泄流量加大, 局部河段防洪形势更为严峻, 对洞庭湖出流顶托作用加强, 出流受阻 ${ }^{[17]}$, 湖区水位相应抬高, 死湖容增大, 洞庭湖调蓄作用减小 ${ }^{[40]}$. 李义天等 ${ }^{[41]}$ 研究表明洞庭湖高水 期调蓄量因下游干流泥沙淤积造成的城陵矶水位逐渐抬高而被动增加, 从而加重了长江中游的防洪压力.

三峡水库调度运行初期, 城陵矶一螺山段河道处于冲刷状态, 降低了洪水位, 从而削弱了长江洪水对湖 口出流排沙的顶托强度, 因此在主汛期洞庭湖湖口泄洪排沙能力均有所提高, 加之汛期入湖水量减少和近 几年退田还湖扩大行蓄洪面积, 使湖区在三峡水库运行初期未发生一处溃堤洪灾 ${ }^{[26]}$. 可见三峡工程引起江 湖水量交换关系的改变,在延缓湖泊淤积和减轻洞庭湖区的洪涝灾害方面起到了积极的作用.

2.3 .2 对水资源供给的影响 进人 21 世纪的近 11 年鄱阳湖枯水程度显著加剧, 尤其是近 5 年来最低水位 不断被刷新, 虽然流域降水和五河来水的变化起主导作用, 但三峡汛末蓄水引起的长江中游来水减少对鄱 阳湖枯季持续低水位起到了加剧的作用 ${ }^{[4244]}$. 洞庭湖的来水量高度集中在汛期, 汛期人湖径流的增减对洞 庭湖全年的水量变化影响很大. 三峡水库调度运行初期, 三口分流显著衰减, 汛期人洞庭湖的水量大幅度减 少, 进而诱发了洞庭湖区连年季节性缺水, 湖区枯季供水紧张, 局部地区取水系统和航道受阻 ${ }^{[26-27]}$.

2.3.3 对水环境的影响 三峡水库蓄水运行改变了通江湖泊水文情势, 进而影响了两湖的水环境状况. 水库 汛末蓄水导致两湖枯季低水位提前出现, 一方面湖泊水量减少可能导致湖泊水环境容量降低, 另一方面湖 水加速下泄人江有利于减少湖泊营养盐滞留; 枯季三峡水库增加泄流, 将不同程度改善两湖枯季水量, 有利 于增加两湖水体自净能力, 但同时也可能增加营养盐在湖泊的滞留. 有研究表明, 洞庭湖水文情势的改变导 致枯季水环境容量上升, 而洪季水环境容量则有所下降 ${ }^{[45]}$. 三峡水库蓄水期鄱阳湖因湖口水位的降低, 大量 湖水注人长江, 湖泊水量的减少降低了水体自净能力, 导致水质下降 ${ }^{[46]}$; 三峡水库泄水期, 江水对鄱阳湖湖

(1) 长江流域防洪规划,2008. 
水出流顶托加重, 延长水滞留时间, 增加人湖污染物滞留, 可能引起水质下降 ${ }^{[47]}$. 此外, 长江倒灌鄱阳湖带来 的泥沙也影响了鄱阳湖水体的透明度 ${ }^{[48]}$.

2.3.4 对水生态系统的影响 鄱阳湖水位的季节性涨落影响了湿地植被的类型、分布范围及演替 ${ }^{[49-52]}$, 同时 还影响了候鸟栖息地的面积和空间分布 ${ }^{[47,53]}$. 近年来与江湖关系变化相关联的洞庭湖水情的变化, 尤其是 低水位出现时间提前、持续时间延长对湖泊湿地生态系统产生了严重的影响, 2011 年 5 月份湖泊水面面积 不足同期的 $45 \%$, 东洞庭湖超过 $1000 \mathrm{hm}^{2}$ 的湿地全部干旱 ${ }^{[54]}$. 三峡工程的运行不同程度上降低了洞庭湖的 水力梯度, 尤其是 4-5 月, 对分布于东洞庭湖的苔草草甸和西洞庭湖的芦苇产生了不利的影响 ${ }^{[55]}$. 湖泊水 情变化对湖泊湿地生态系统的长期影响可能包括外来物种的人侵 ${ }^{[56-58]}$ 、典型湖泊湿地演变为陆地生态系 统. 季节性水位变化导致鱼类生长期的湖泊水面减小, 影响长江繁殖的鱼苗进人湖泊生长发育 ${ }^{[8]}$.

\section{3 江湖关系研究的趋势}

纵观长江中游通江湖泊江湖关系研究, 在江湖关系的演变过程、江湖关系变化的成因及效应等方面已 取得了一定的进展, 但在对江湖关系的表征、气候变化与重大工程对江湖关系影响的贡献区分、江湖关系对 湖泊水文节律、水环境和水生态影响机理、江湖关系调整后两湖对长江的影响等方面尚存在问题, 这些问题 也是未来通江湖泊江湖关系研究的重点, 需要深人研究.

\section{1 表征江湖关系的指标}

在对江湖关系的认识方面, 由于江一湖相互作用的复杂性, 已有的研究多侧重于江湖关系的一个方面, 目前尚无一套系统、综合、权威的江湖关系表征方法. 如何构造具有指示意义的复合指标来表征江湖关系及其 变化是未来长江中游通江湖泊江湖关系研究的难点. 对于鄱阳湖而言, 江湖关系的表征应涵盖江湖水量及物 质能量交换的通量、长江对鄱阳湖的顶托作用强度; 对于洞庭湖而言, 江湖关系的表征应包涵江湖水沙交换通 量、荆江三口分流分沙、城陵矶出流长江顶托 (代表性站点的水位流量关系及出口水力比降). 由于长江中游通 江湖泊的水情具强烈的季节性变动特征,江湖关系的表征还应反映年、季、月等多个时间尺度特征.

\section{2 人类活动与气候变化对江湖关系影响的区分}

江湖关系变化是人类活动与流域气候变化综合作用的结果. 已有的研究分析了江湖关系变化的影响因 素, 重点考虑了不同时期人类活动尤其是重大水利工程的影响. 因此, 如何综合考虑人类活动与流域气候变 化对江湖关系变化的联合影响, 并且定量区分其影响贡献率是江湖关系研究的一个核心问题. 根据目前已 有的研究, 三峡工程对两湖水情的影响一般不超过 $8 \% \sim 15 \%$, 但对其生态环境的影响分量, 还缺少有效的手 段和方法 ${ }^{[32]}$.

\section{3 三峡工程对江湖关系变化长期影响的跟踪研究}

近 10 年来, 三峡工程蓄水运行对长江中下游生态环境的影响引起了广泛的关注和争议 ${ }^{[34]}$. 虽然已有研 究揭示了三峡工程改变了长江中游江湖关系, 进而改变了洪枯水的流量过程, 产生一系列水资源、水环境和 水生态问题, 但是从国际上在某些大型水利工程兴建几十年后凸显的一系列严重生态环境问题 ${ }^{[21]}$ 来看, 已 有的研究还远远不足以阐明三峡工程对长江中游江湖关系的长期影响及其可能的效应. 长江中游江湖水沙 关系复杂、河道边界条件复杂, 三峡工程及上游大型水利工程运行对长江中下游江湖冲淤演变、两湖水情以 及生态环境的影响非常深远. 江湖关系对湖泊水文节律、湖泊水环境和水生态影响机理和趋势, 需开展长期 的跟踪监测和深入研究.

\section{4 江湖关系调整背景下的江湖关系健康评价}

江湖关系变化将改变江湖水文情势, 进而直接影响到江湖防洪、水资源供给、水环境及水生态的安全, 维系江湖两利的健康江湖关系是长江中游江湖关系研究的根本目的, 而江湖关系健康评价指标体系的构建 和指标健康阈值的确定又成为江湖关系研究的一个难题. 从总体上看, 长江对两湖 (鄱阳湖和洞庭湖) 的影 响远大于两湖对长江的影响, 因此江湖关系调整下的江湖关系健康研究的核心是与江湖相互作用的特征水 情要素关联的湖泊水安全研究.

传统湖泊水安全评价 ${ }^{[59]}$ 较多考虑湖泊本身的水位、流量等特征指标, 较少考虑水环境和水生态指标, 更 没有涉及这些水安全指标与相关水情要素变化的关联. 江湖相互作用的水情要素变化, 是连接湖泊水安全 
与江湖关系的纽带, 直接控制通江湖泊水安全情势. 目前已有的研究, 在关注湖泊高水位特征的湖泊防洪安 全 ${ }^{[60-61]}$ 、关注湖泊低水位特征的湖泊水资源供给安全 ${ }^{[42,54]}$ 两个方面虽有所涉及, 但是在湖泊防洪及水资源 供给安全等级划分标准及阈值确定方面尚缺乏深人的研究.

就湖泊水环境和水生态安全评价方面, 长江中游两湖复杂湖泊水文水动力条件与水环境、水生态的关 系研究尚未开展. 其他区域的研究表明, 湖泊水体营养状态指数 ${ }^{[62-64]}$ 和营养盐滞留系数 ${ }^{[65-66]}$ 是受水文情势 和水动力学条件影响的、反映湖泊水体富营养化的重要指标. 湖泊水生态安全包括湖泊洲滩湿地生态与水 域生态安全两个方面. 湖泊洲滩湿地植被分布面积、地表植物生物量和植物多样性指数是衡量湿地生态系 统状况的重要指标, 这些指标与湖泊水位的年际、季节性变动密切相关 ${ }^{[51]}$. 硅藻是河湖生态系统中的优势藻 类, 已成为水环境与水生态监测的重要生物指标 ${ }^{[67-68]}$, 硅藻多样性指数受到水动力条件尤其是水体流速的 影响 ${ }^{[69]}$. 上述研究可为长江中游江湖关系调整背景下的湖泊水环境和水生态安全指标体系的构建提供借 鉴,在水环境、水生态安全指标与关键水情要素关系、安全指标标准及阈值确定方面需深人探讨.

\section{5 江湖关系健康调控原理和江湖水系重大水利工程一体化优化调度研究}

长江中游通江湖泊优良的生态环境现状, 很大程度上依赖于与长江快速的水体交换和发育良好的洲滩 湿地. 江湖关系变化必然改变湖泊水文、水动力的时空格局, 引起湖泊内部污染物质的输移过程和湖泊水环 境容量改变, 在特定的条件下可能导致局部水体环境质量恶化、富营养化加重和藻类水华暴发, 同时这些变 化又影响着湖泊湿地植被生长和发育, 反过来改变湿地水动力、水质净化能力和珍稀候鸟栖息地生境等. 阐 明江湖关系改变的这些综合效应, 必须揭示水沙、污染物质与湖泊生物之间的相互影响、相互制约关系. 目 前这方面的研究还较薄弱, 相关成果也较为分散, 难以为预测江湖关系变化带来的湖泊水文、水环境和生态 演变提供科学支撑. 深人认识江湖关系变化效应, 一方面可提出有效措施以应对江湖关系变化带来的不利 影响, 实现江湖两利目标; 另一方面, 也可更好地预估引起江湖关系重大改变的水利工程建设, 如鄱阳湖水 利枢纽工程 (湖口建闸)、跨流域调水和水系调整等对长江中下游地区生态环境的影响, 避免造成失误. 在加 快环鄱阳湖和环洞庭湖生态经济圈建设的背景下, 中游水环境和生态压力将进一步加重, 围绕协调重大水 利工程影响下江湖水资源、水环境和生态关系问题, 特别是像长江中游地区这样复杂庞大的江河关系的协 调, 目前国内外都没有可以借鉴的成功经验或案例. 因此, 迫切需要深人开展保障长江中游水安全的重大应 用基础理论研究, 以揭示重大水利工程与大型江湖系统相互作用的过程与动力学机制, 指导实践的需求.

当前, 长江中游通江湖泊面临前所未有的水安全压力, 重大水利工程具有良好的调节水沙能力. 充分发 挥现有重大水利工程的效益, 将长江三峡水库与洞庭湖人湖四水和鄱阳湖人湖五河流域大中型水库纳人统 一的调度系统, 开展江湖水系重大水利工程一体化优化调度, 是改善和维持江湖关系健康最为经济、可行的 手段. 通过重大水利工程联调联控一体化调度改善下游水沙条件和水生态环境状况, 正受到各方面的高度 重视, 也取得了良好的成效. 如黄河调水调沙试验显著改善黄河中下游水沙情势和水资源供给状况, “引江 济太” 和“引江济巢” 等调水冲污实践对改善湖泊水环境和水资源供给状况发挥了重要作用. 因此, 在江湖关 系变化的机制和效应研究基础上, 综合多学科知识构建大型河湖系统的健康评价理论与方法, 明确水安全 要素健康阈值, 以此为条件, 研究以江湖水系重大水利工程群联合调度为核心的江湖关系优化调控准则和 方法,是当前亟须开展并解决的基础理论问题.

\section{4 参考文献}

[ 1 ] 杨桂山. 长江水问题基本态势及其形成原因与防控策略. 长江流域资源与环境,2012,21(7):821-830.

[2]卢金友,罗恒凯. 长江与洞庭湖关系变化初步分析. 人民长江, 1999,30(4):24-26.

[ 3 ] Hu Q, Feng S, Guo H et al. Interactions of the Yangtze River flow and hydrologic processes of the Poyang Lake, China. Journal of Hydrology, $2007,347: 90-100$.

[ 4 ] 尹发能. 洪湖自然环境演变研究. 人民长江,2008,39(5):19-22.

[ 5 ] Bonnet MP, Barroux G, Martinez JM et al. Floodplain hydrology in an Amazon floodplain lake( Lago Grande de Curuai). Journal of Hydrology, $2008, \mathbf{3 4 9}: 18-30$.

[ 6 ] Lesack LFW, Melack JM. Flooding hydrology and mixture dynamics of lake water derived from multiple sources in an Amazon floodplain lake. Water Resources Research, 1995 ,31 :329-345. 
[ 7 ] 李义天,邓金运,孙昭华等. 泥沙淤积与洞庭湖调蓄量变化. 水利学报,2000,12:48-52.

[ 8 ] 蔡其华. 健康长江与洞庭湖治理. 水利水电快报, 2007, 28 (9) :1-3,8.

[ 9 ] Guo H, Hu Q, Zhang Q et al. Effects of the Three Gorges Dam on Yangtze River flow and river interaction with Poyang Lake, China: 2003 - 2008. Journal of Hydrology, 2012,416:19-27.

[10］郭 华, Hu Qi, 张 奇等. 鄱阳湖流域水文变化特征成因及旱涝规律. 地理学报, 2012,67(5):699-709.

[11］方春明,曹文洪,毛继新等. 鄱阳湖与长江关系及三峡蓄水的影响. 水利学报,2012,43(2): 175-181.

[12] 赵军凯,李九发,戴志军等. 枯水年长江中下游江湖水交换作用分析. 自然资源学报,2011,26(9): 1613-1627.

[13］李学山, 王翠平. 荆江与洞庭湖水沙关系演变及对城螺河段水情影响分析. 人民长江, 1997,28(8):6-8.

[14] 许全喜,胡功宇,袁 晶. 近 50 年来荆江三口分流分沙变化研究. 泥沙研究,2009, (5):1-8.

[15] 卢承志. 江湖关系的现状及问题. 湖南水利水电, 2005, (6) :22-25.

[16] 赖锡军,姜加虎, 黄 群. 三峡工程蓄水对鄱阳湖水情的影响格局及作用机制分析. 水力发电学报, 2012,31(6): $132-136,148$.

[17] 胡旭跃,马利军,程永舟等. 洞庭湖演变机理及地貌临界特征分析. 人民长江,2011,42(15): 73-76.

[18] Yin HF, Liu GR, Pi JG et al. On the river-lake relationship of the middle Yangtze reaches. Geomorphology, 2007,85: 197-207.

[19] Du Y, Xue HP, Wu SJ et al. Lake area changes in the middle Yangtze region of China over the 20th century. Journal of Environmental Management, $2011,92: 1248-1255$.

[20] Wang SJ, Chen ZY, Smith DG. Anastomosing river system along the subsiding middle Yangtze River basin, southern China. Catena, $2005,60: 147-163$.

[21］杨桂山,马超德, 常思勇. 长江保护与发展报告 2009. 武汉:长江出版社,2009.

[22] Dai SB, Yang SL, Zhu J et al. The role of Lake Dongting in regulating the sediment budget of the Yangtze River. Hydrology and Earth System Sciences, 2005,9 :692-698.

[23] Xu KH, Milliman JD. Seasonal variations of sediment discharge from the Yangtze River before and after impoundment of the Three Gorges Dam. Geomorphology, 2009,104:276-283.

[24] 来红州,莫多闻,苏 成. 洞庭湖演变趋势探讨. 地理研究,2004,23(1):78-86.

[25] Zhang Q, Liu Y, Yang GD et al. Precipitation and hydrological variations and related associations with large-scale circulation in the Poyang Lake basin, China. Hydrological Processes, $2011,25: 740-751$.

[26] 李景保, 常 疆, 吕殿青等. 三峡水库调度运行初期荆江与洞庭湖区的水文效应. 地理学报, 2009, 64 (11): 1342-1352.

[27］李正最,谢悦波,徐冬梅. 洞庭湖水沙变化分析及影响初探. 水文,2011,31(1):45-53.

[28］黎昔春,段文忠,余明辉等. 洞庭湖区防洪问题研究. 泥沙研究, 2001, (5) :54-58.

[29] Dai ZJ, Du JZ, Li JF et al. Runoff characteristics of the Changjiang River during 2006: Effect of extreme drought and the impounding of the Three Gorges Dam. Geophysical Research Letters, 2008,35(7) :L07406. 1-L07404. 6.

[30 ] Yang SL, Zhang J, Xu XJ. Influence of the Three Gorges Dam on downstream delivery of sediment and its environmental implications, Yangtze River. Geophysical Research Letters, 2007,34(10) :L10401.1-L10401. 5.

[31] 方春明, 毛继新, 陈绪坚. 三峡工程蓄水运用后荆江三口分流河道冲淤变化模拟. 中国水利水电科学研究院学报, 2007,5 (3) : 181-185.

[32］杨桂山,朱春全,蒋志刚. 长江保护与发展报告 2011. 武汉:长江出版社,2011.

[33] 汪迎春, 赖锡军, 姜加虎等. 三峡水库调节典型时段对鄱阳湖湿地水情特征的影响. 湖泊科学, 2011, 23 (2): 191-195.

[34] Zhang Q, Li L, Wang YG et al. Has the Three-Gorges Dam made the Pongyang Lake wetlands wetter and drier? Geophysical Research Letters, $2012,39: 1-7$.

[35] Liu YB, Wu GP, Zhao XS. Recent declines in China's largest freshwater lake:trend or regime shift? Environmental Research Letters, $2013,8: 1-9$.

[36] Shankman D, Keim BD, Song J. Flood frequency in China's Poyang Lake region: Trends and teleconnections. International Journal of Climatology, 2006,26:1255-1266.

[37] Zhang Q, Zhou Y, Singh VP et al. The influence of dam and lakes on the Yangtze River streamflow: long-range correlation and complexity analyses. Hydrological Processes, $2012,26: 436-444$.

[38 ] Shankman D, Liang Q. Landscape changes and increasing flood frequency in China's Poyang Lake region. Professional Ge- 
ographer, $2003,55: 434-446$.

[39] Nakayama T, Watanabe M. Role of flood storage ability of lakes in the Changjiang River catchment. Global and Planetary Change, $2008,63: 9-22$.

[40］吴作平,杨国录,甘明辉. 荆江一洞庭湖水沙关系及调整. 武汉大学学报:工学版,2002,35(3):5-8.

[41］李义天,孙昭华,邓金运. 洞庭湖临界人湖洪量变化及对防洪的影响. 安全与环境学报,2001,1(1):13-18.

[42］闵 骞,占腊生. 1952-2011 年鄱阳湖枯水变化分析. 湖泊科学,2012,24(5):675-678.

[43] 赖锡军,姜加虎, 黄 群. 三峡工程蓄水对洞庭湖水情的影响格局及其作用机制. 湖泊科学, 2012,24(2): 178-184.

[44] 董增川,梁忠民,李大勇等. 三峡工程对鄱阳湖水资源生态效应的影响. 河海大学学报: 自然科学版, 2012,40(1): 13-18.

[45] Yang SJ, Hu HY, Hao ZC. Trend forecast for the influence of the Three Gorges project on the water environmental capacity of Dongting Lake. 2009 Asia-Pacific Power and Energy Engineering Conference( Appeec), Vols 1-7, 2009:2454-2457.

[46] Wu L, Li M, Guo Y et al. Influence of Three Gorges Project on water quality of Poyang Lake. Procedia Environmental Sciences, $2011, \mathbf{1 0}: 1496-1501$.

[47 ] 吴龙华. 长江三峡工程对鄱阳湖生态环境的影响研究·水利学报,2007,S1 :586-591.

[48] Cui LJ, Wu GF, Liu YL. Monitoring the impact of backflow and dredging on water clarity using MODIS images of Poyang Lake, China. Hydrological Processes, 2009 ,23:342-350.

[49] Dronova I, Gong P, Wang L. Object-based analysis and change detection of major wetland cover types and their classification uncertainty during the low water period at Poyang Lake, China. Remote Sensing of Environment, 2011, 115: 3220-3236.

[50] 胡振鹏, 葛 刚, 刘成林等. 鄱阳湖湿地植物生态系统结构及湖水位对其影响研究. 长江流域资源与环境, 2010,19 (6) :597-605.

[51］余 莉,何隆华,张 奇等.三峡工程蓄水运行对鄱阳湖典型湿地植被的影响. 地理研究,2011,30(1):134-144.

[52］张丽丽,殷峻暹, 蒋云钟等. 鄱阳湖自然保护区湿地植被群落与水文情势关系. 水科学进展, 2012,23 (6) : 768-775.

[53] 刘成林,谭胤静,林联盛等. 鄱阳湖水位变化对候鸟栖息地的影响. 湖泊科学,2011,23(1):129-135.

[54] Sun Z, Huang Q, Opp C et al. Impacts and implications of major changes caused by the Three Gorges Dam in the middle reaches of the Yangtze River, China. Water Resource Management, 2012,26: 3367-3378.

[55] 李 倩, 曾光明, 黄国和等. 三峡工程对洞庭湖水力梯度及其湿地植物生长的影响. 安全与环境学报, 2005,5(1): 11-15.

[56] Ding JQ, Mack RN, Lu P et al. China's booming economy is sparking and accelerating biological invasions. Bioscience, $2008,58: 317-324$.

[57］谢永宏,陈心胜.三峡工程对洞庭湖湿地植被演替的影响.农业现代化研究,2008,29(6):684-687.

[58] 葛 刚, 李恩香, 吴和平等. 鄱阳湖国家级自然保护区的外来人侵植物调查. 湖泊科学, 2010,22(1):93-97.

[59］金菊良,吴开亚,魏一鸣. 基于联系数的流域水安全评价模型. 水利学报,2009,36(4):401-409.

[60］闵骞. 关于建立洪水等级划分模式的初步构思——鄱阳湖为例. 水文,1996,2:43-47.

[61] 闵寒. 鄱阳湖洪水灾变特征的分析. 江西水利科技, 1997,23(2):86-93.

[62］王明翠,刘雪芹,张建辉. 湖泊富营养化评价方法及分级标准. 中国环境监测, 2002,18 (5): 47-50.

[63] Soballe DM, Kimmel BL. A large-scale comparison of factors influencing phytoplankton abundance in rivers, lakes, and impoundments. Ecology, 1987, 68: 1943-1954.

[64] Westlake DF. Primary production. In: Cren EDL, Lowe-Mcconnell RH eds. The functioning of freshwater ecosystems. London: Cambridge University Press, 1980.

[65］冉祥滨,于志刚,姚庆祯等. 水库对河流营养盐滞留效应研究进展. 湖泊科学,2009,21(5):614-622.

[66] Morris GL, Fan J. Reservoir sedimentation handbook: design and management of dams, reservoirs and watersheds for sustainable use. New York: McGraw-Hill, 1998.

[67] 董旭辉,羊向东, 王 荣等. 长江中下游地区湖泊富营养化的硅藻指示性属种. 中国环境科学, 2006, 26 (5): 570-574.

[68 ] Kelly M, Juggins S, Guthrie R et al. Assessment of ecological status in UK rivers using diatoms. Freshwater Biology, 2008, 53(2) : 403-422.

[69] Denys L. Relation of abundance-weighted averages of diatom indicator values measured environmental conditions in standing freshwaters. Ecological Indicators, 2004, 4:255-275. 